\title{
High School Students' Geometric Thinking, Problem Solving and Proof Skills
}

\author{
Hülya KILIÇ* \\ Yeditepe University, İstanbul, TURKEY \\ Received: 13.12 .2012 \\ Accepted: 10.05 .2013
}

\begin{abstract}
The aim of this paper is to present the findings of a pilot study which was designed to investigate the effects of using dynamic geometry software on the tenth grade students' geometric thinking, problem solving and proof skills. It was a quasi-experimental study consisted of 49 students from six different high schools around Istanbul. In the treatment groups, the students engaged with five dynamic geometry activities in the geometry lessons throughout the semester. Although no significant differences between the groups were observed, in the treatment groups, the students' mean scores for each type of test increased significantly. The students' answers for each item in the tests were also analyzed. It is found that students' mean scores for each item were quite low such that they did not know the definitions of basic geometric concepts and the relationships between them and also they were not able to solve geometry problems and prove given arguments.
\end{abstract}

Key words: dynamic geometry software, geometric thinking, problem solving, proof, secondary.

DOI No: http://dx.doi.org/10.12973/nefmed160

\section{Summary}

\section{Purpose}

Geometry is "a complex interconnected network of concepts, ways of reasoning, and representation systems that is used to conceptualize and analyze physical and imaged spatial environments" (Battista, 2007, p.843). Thus, learning geometry entails visualization and construction of images of geometric concepts and making appropriate relationships between the concepts. Although the aim of our geometry curricula is to enable students make appropriate relationships between geometric concepts and justify generalizations and proofs, and to foster students' reasoning and critical thinking skills (MEB, 2010), the results of national and international mathematics assessments reveal that Turkish students fail to achieve those goals (ÖBBS, 2009; PISA, 2009; TIMMS, 2007).

\footnotetext{
* Corresponding author: Hülya KILIÇ, Assist. Prof., Secondary Mathematics Education, Yeditepe University, Istanbul, TURKEY.

E-mail: hulya.kilic@yeditepe.edu.tr
} 
The studies investigating the effective ways of teaching geometry suggest that dynamic geometry software which provides opportunities for students to construct geometric figures and manipulate them easily on the computer helps students visualize geometric concepts and understand geometric rules, generalizations and relationships between the concepts (Healy \& Hoyles, 1999; Jones, 2000; Marrades \& Gutierrez, 2000). Using dynamic geometry software in geometry lessons may be effective in terms of increasing Turkish students' geometry achievement, developing their higher order thinking skills. Therefore, the aim of this study was to investigate the effects of using dynamic geometry software on students' geometric thinking, problem solving and proving skills.

\section{Results}

Three types of tests, namely, Geometric Thinking Test (GTT), Geometry Achievement Test (GAT) and Geometry Proof Test (GPT) were administered before and after the study to both treatment and control groups. The validity and reliability of the tests were satisfied. The pretest results for each group were compared. There were no statistical difference between GTT and GAT but there was significant difference between GPT. The posttest comparisons showed that there were no significant difference between the groups in terms of GTT, GAT and GPT results. The pretest and posttest results for each group were compared. For experiment group significant differences were obtained in terms of all types of tests but for control group there was significant difference in terms of geometry achievement. However, the mean score of the tests were quite low. The mean scores and the maximum scores for GTT, GAT and GPT post tests were as follows: 44/81, 29/82 and 11/45. The items for each test were analyzed. The mean score of the seventh item of GTT (drawing geometric figures), the sixth item of GAT (similarity) and the first item of GPT (exterior angle of a triangle is sum of non-adjacent interior angles) was the highest with respect to other items.

\section{Discussion}

The mean scores of the tests and test items revealed that students' geometric thinking levels, geometry achievement and proof skills were low. This finding was compatible with the ÖBSS, PISA and TIMSS results. However, significant increases in the mean scores of treatment group's tests support the fact that engaging with dynamic geometry activities helps students to understand and visualize geometric concepts. Although skill development entails more frequent practices, five dynamic geometry activities were likely to contribute to the improvement of students' geometric thinking and problem solving skills. Similar studies also supported this finding that the effects of using dynamic geometry software to teach or learn geometry can be seen even after a few applications. 
The item analysis revealed that students did not possess conceptual understanding of geometric terms and their geometric abilities were at comprehension level. They had an image of the given concept in their mind and they attempted to define the concept in terms of that image. However, those images were limited to the cases they experienced before. For instance, they defined an angle bisector as a line segment because an angle bisector of a triangle is drawn to be a line segment. Furthermore, they did not know the properties related with the given concept. For instance, the centroid of a triangle is located on the median with a ratio of $2: 1$. Because their geometric abilities were mostly at comprehension level, they failed to solve geometry problems and prove given theorems.

\section{Conclusion}

The findings of this pilot study revealed that Turkish high school students' geometric thinking, problem solving and proof skills were low as supported by the results of national and international assessment studies. However, using dynamic geometry activities in which students construct geometric figures, manipulate them, explore the relationships between them and make generalizations or proofs are likely to improve students' such skills. Hence, using dynamic geometry software should be a part of geometry lessons and students should be given opportunities to engage with dynamic geometry activities. 


\title{
Lise Öğrencilerinin Geometrik Düşünme, Problem Çözme ve İspat Becerileri
}

\author{
Hülya KILIÇ ${ }^{\dagger}$
}

Yeditepe Üniversitesi, İstanbul, TÜRKİYE

Makale Gönderme Tarihi: 13.12.2012

Makale Kabul Tarihi: 10.05 .2013

Özet - Bu çalışmanın amacı, dinamik geometri yazılımlarının 10. sınıf öğrencilerinin geometrik düşünme, geometri başarısı ve ispat yapma becerisi üzerindeki etkilerini incelemektir. Bu makalede, bu amaçla gerçekleştirilen yarı deneysel pilot çalışmadan elde edilen bulgular tartışılacaktır. Çalışmaya, İstanbul ilindeki altı liseden 227 öğrenci katılmış ancak 49 öğrencinin verileri analiz edilmiştir. Öğrencilere geometrik düşünme, problem çözme ve ispat becerilerini ölçmeye yönelik üç farklı test uygulanmış, çalışma boyunca deney grubundaki öğrencilerle dinamik geometri yazılımının kullandığı beş etkinlik yapılmıştır. Son testlerde gruplar arasında anlamlı bir fark bulunmamış ancak deney grubunda üç testin ortalamalarında anlamlı artı̧̧lar olduğu görülmüştür. Bununla beraber, öğrencilerin testler bazında ortalamalarının genel olarak düşük olduğu, temel geometrik kavramları tanımlayamadıkları, kavramlar arasındaki ilişkileri kuramadıkları, kavram bilgisini farklı durumlarda uygulayamadıkları ve ispat becerilerinin düşük olduğu tespit edilmiştir.

Anahtar kelimeler: dinamik geometri yazılımları, geometrik düşünme, problem çözme, ispat, lise.

\section{Giriş}

Matematiğin en eski dallarından biri olan geometri, Battista (2007) tarafindan "kavramların, akıl yürütme yollarının, ve fiziksel ve düşünsel uzamsal çevrelerin zihinde canlandırılması ve analiz edilmesi için kullanılan temsili gösterim sistemlerin oluşturduğu birbirine bağlı birçok parçadan oluşan bir ağ sistemi” olarak tanımlanır (sf. 843). Bu bağlamda geometri öğretiminin de öğrencilerin zihinde canlandırabilme, eleştirel düşünme, üç boyutlu nesneleri iki boyuta indirgeyebilme, problem çözme, varsayımda bulunma, mantıklı çıkarımlarda bulunabilme ve ispat becerilerinin gelişimine katkıda bulunması beklenir (Jones, 2002). Her ne kadar geometri öğretim programlarında öğrencilerin bu tür becerileri geliştirmesi hedeflenmiş olsa da (Milli Eğitim Bakanlığı [MEB], 2010) gerek ulusal gerekse uluslararası sınavlardan elde edilen sonuçlar öğrencilerin bu becerileri geliştiremediğini ortaya koymaktadır.

\footnotetext{
†' İletişim: Hülya Kılıç, Yrd. Doç. Dr., Ortaöğretim Matematik Öğretmenliği, Yeditepe Üniversitesi, İstanbul, TÜRKIYE.

E-posta: hulya.kilic@yeditepe.edu.tr
} 
Uluslararası matematik ve fen başarısını karşılaştırmalı olarak göstermeyi amaçlayan Trends in International Mathematics and Science Study (TIMSS) araştırmasının 2007 yılında yapılan değerlendirme sonuçlarına göre Türk öğrencilerin en çok geometride başarısız olduğu görülmektedir. Değerlendirmeye katılan ülkelerin ortalama matematik başarısının 500 puan alındığ1 değerlendirmede, Türkiye'nin genel ortalaması 432 puandır. Sayılar, cebir, geometri, veri ve olasılık konu başlıkları altında 411 puan ile en düşük başarı geometridedir. Diğer uluslararası değerlendirme sinavı olan Program for International Student Assessment (PISA) 2009 yılı sonuçlarına göre ise Türkiye'nin ortalaması 445 puan olup 496 puan olan dünya ortalamasının altındadır. PISA sınavına göre Türk öğrencilerin ortalama matematik okuryazarlığı 2. düzey ve altındadır. PISA değerlendirmesine göre 2. düzeye erişmiş öğrenciler ancak doğrudan çıkarım yapmaktan başka bir beceriye gerek olmayan durumları tanıyabilir ve yorumlayabilirler. Bu öğrenciler, tek bir kaynaktan gerekli bilgiyi elde edebilir ve sadece bir gösterim biçimini kullanabilirler. Bu düzeydeki öğrenciler temel algoritmaları, formülleri, alışılageldik işlem yollarını kullanabilirler. Doğrudan ispat gibi basit akıl yürütmeleri yapabilirler ve sonuçlar üzerinde görülenin ötesine geçmeyen yorumlar yapabilirler. $\mathrm{Bu}$ durum, lise öğretim programında belirtilen, geometrik ispatlarda sentetik, analitik ve vektörel yaklaşımları kullanma, yapılan çıkarımların ve genellemelerin geçerliliğini sorgulama ve geometrik nesneleri cebirsel nesneler haline dönüştürme gibi üst düzey düşünme becerileri hedefleriyle bağdaşmamaktadır. Ayrıca Öğrenci Başarılarının Belirlenmesi Sınavı (ÖBSS) 2009 yılı raporuna göre 9. ve 10. sınıf lise öğrencilerinin matematik başarısı sırasıyla, \%32 ve \%36'dır. Öğrenciler arasında yapılan anket sonuçlarına göre ise öğrencilerin en çok zorlandıkları ders geometridir. Gerek ilköğretim ikinci kademe gerekse lise öğrencilerinin geometri başarısının düşük olması bu konuda acil ve etkili tedbirler alınması gereğini doğurmuştur.

Geometrik düşünme becerileri ile ilgili çalışmalar ilk olarak 1950li yılların sonuna doğru Hollandalı matematik eğitimcisi van Hiele tarafından yayınlanmıştır. Van Hiele geometrik düşünmenin beş düzeyi olduğundan bahsetmiştir: görsel (0. düzey), analitik (1. düzey), informal tümdengelim (2. düzey), formal tümdengelim (3. düzey), soyut çıkarım (4. düzey) (Usiskin, 1982). Görsel düzeyde, kişi geometrik şekilleri ve aralarındaki temel farkı örneğin, kare ile dikdörtgeni ayırt edebilir. Analitik düzeyde, şekillerin genel özelliklerini tanımlayabilir. Örneğin, dikdörtgenin dört kenarı vardır ve tüm açıları dik açıdır. İnformal tümdengelim düzeyinde ise kişi benzer özelliklerine göre şekilleri sınıflandırabilir ve "dikdörtgen paralelkenarın özel bir halidir" gibi basit çıkarımlar yapabilir. Formal 
tümdengelim düzeyinde teorem ve ispatın önemini bilir, teorem ispatlarını anlar ve kendisi de ispat yapabilir. Son düzeyde ise soyut çıkarımlarda bulunabilir ve farklı aksiyomatik sistemler ve bu sistemler arasındaki ilişkiyi anlayabilir. Clements ve Battista (1992), van Hiele'nin bu beş düzeyi öncesi bir düzey daha olduğunu belirtmiş ve bu düzeyi tanıma öncesi (prerecognition) olarak isimlendirmiştir. Bu düzeyde kişinin zihninde henüz şekillerin protipleri oluşmamıştır. Örneğin, kare ve dikdörtgen farklı şekiller olarak görülmez. Van Hiele'nin öne sürdüğü geometrik düşünme düzeyleri ile ilgili pek çok araştırmacı çalışma yapmıştır. Yapılan çalışmalar, van Hiele'nin teorisinin doğruluğu kadar eksik veya açıklayamadığı noktaların olduğunu da ortaya koymaktadır (ayrıntılar için bakınız: Battista, 2007). Driscoll (2007), geometrik düşünmeyi geliştirmek için kişinin bazı zihinsel alışkanlıklar kazanması gerektiğini söylemektedir ve bu alışkanlıkları aklın geometrik alışkanlıkları (geometric habits of mind) olarak tanımlamaktadır. Driscoll'e göre aklın dört geometrik alışkanlığı vardır: bağlantılar arasındaki nedenleri ortaya koyma, geometrik olguları genelleştirme, değişmezleri inceleme, keşif ve yansıtma arasında denge oluşturma. Driscoll, bağlantılar arasındaki nedenleri ortaya koyma alışkanlığını, kişinin verilen şekillerin hangi yönleriyle birbirlerine benzediğini veya birbirlerinden farklı olduğunu sorgulaması olarak açıklar. Genelleştirme alışkanlığı kişinin gözlenen bir olayın farklı durumlarda da geçerli olup olmadığını sorgulamasıdır. Genelleştirme alışkanlığı ile Driscoll geometrik düşünmede tümevarımın önemini vurgulamakta; bu yönüyle, geometrik düşünme düzeyleri arasında tümdengelimi koyan van Hiele'den farklılaşmaktadır. Aklın diğer bir geometrik alışkanlığı olan değişmezleri inceleme; yansıma, simetri, öteleme gibi işlemler altında ilk başta verilen durum ile son durum arasında nelerin değişip değişmediğinin sorgulanmasıdır. Driscoll, son alışkanlık olan keşif ve yansıtma arasındaki dengeyi kurmayı, problem çözerken kişinin ne yaptığının farkında olması, çözümün her aşamasında ve çözüm sonrasında bulduğu sonuçların doğruluğunu sorgulaması olarak tanımlar. Tanımlanan bu alışkanlıklar birbirinden bağımsız alışkanlıklar değil, aksine problem çözme süreci içinde ihtiyaç duyulan birbirine bağlı alışkanlıklardır (Driscoll, 2007).

Teknolojinin yaygınlaşması ile birlikte eğitim amaçlı teknolojinin nasıl kullanılacağı, teknoloji kullanımının öğrenmeye etkisi gibi konular daha da önem kazanmakta konuyla ilgili çalışmalar yapılmaktadır. Yirmi yılı aşkın süredir hem eğitimciler hem de yazılımcılar dinamik geometri programları üzerinde çalışmaktadır. Bu programlar yalnızca öğrencileri öğrenmek için motive etmez aynı zamanda geometrik kavramları keşfetmelerine olanak sağlayarak, öğrenme sürecini hızlandırır (Battista, 2007). Geometri derslerinin temel amaçlarından biri de öğrencilerin uzamsal ve geometrik düşünme, akıl yürütme ve ispat 
becerilerini geliştirmektir (MEB, 2010). Dinamik geometri yazılımlarının kullanıldığı öğrenme ortamları (dinamik geometri ortamı), öğrencilerin bu becerilerinin geliştirilmesine olanak sağlamaktadır (ör.: Güven, 2008; Healy \& Hoyles, 1999; Jones, 2000; Olkun \& Altun, 2003; Ubuz, Üstün, \& Erbaş, 2009). Çünkü öğrenciler, dinamik ortamlarda geometrik çizimlerin esaslarına göre çizdikleri şekilleri istedikleri gibi değiştirebilir, buna göre değişen veya değişmeyen kısımlar arasındaki ilişkileri rahatça görebilir, gözlemlerine ve sayısal verilere dayanarak çıkarımlarda veya genellemelerde bulunabilirler (Marrades \& Gutaerrez, 2001). Dinamik geometri ortamları, öğrencilerin tümdengelim açıklamalarını oluşturmada, ispat ve ispat etme için fikir geliştirmeye temel hazırlamada önemli bir role sahiptir (Jones, 2000). Heinze ve arkadaşları (Heinze, Cheng, Ufer, Lin, \& Reiss, 2008) geometrik ispatın verilen bilgiyi ve bilginin durumunu anlamak, çözüm için gerekli dayanak, tez ve sonuçları tanımlamak, çok basamaklı ispatlarda ara basamakları oluşturmak ve yapılacak olanları bir sıraya koyup düzenlemek olduğunu söyler. Dinamik geometri ortamlarında öğrencilerin bu aşamaları takip etmesi daha kolay olmaktadır. Çünkü öğrenciler, dinamik geometri yazılımını kullanırken belli bir sıra takip etmek zorundadır (Scher, 2005). Örneğin, bir kare oluşturmak için aynı uzunlukta doğru parçaları çizilip bunların birleştirilmesi doğru bir yaklaşım değildir. Karenin, hem eş kenarlara hem de eş açılara sahip olması gerekir.

Yapılan araştırmalarda, dinamik geometri yazılımlarının, öğrencilerin görselleştirme, geometrik düşünme ve ispat becerilerinin gelişmesine olumlu katkılarda bulunduğuna dair bulgular elde edilmesi, ulusal veya uluslararası değerlendirmelerde özellikle geometri derslerinde düşük başarı gösteren Türk öğrencilerin geometri başarılarını artırmaya yönelik olarak bu tür dinamik geometri yazılımların kullanabileceğini ve bunun etkilerini araştırma gereği ortaya koymuştur. Bu nedenle, 10. sınıf geometri dersinde öğrencilerin zaman zaman dinamik geometri etkinlikleri gerçekleştirmelerinin, geometrik düşünme, problem çözme ve ispat becerilerini nasıl etkileyeceği araştırılacaktır. Bu makalede, yapılacak bu çalışmanın öncesinde gerçekleştirilen pilot çalışmanın bulguları tartışılacaktır.

\section{Yöntem}

\section{Araştırma Modeli}

$\mathrm{Bu}$ çalışma, ön test-son test kontrol gruplu yarı deneysel bir yapıdadır. Araştırmanın ana problemi, öğrencilerin dinamik geometri yazılımlarını kullanılarak gerçekleştirdikleri etkinliklerle zenginleştirilmiş geometri dersleri sonrasındaki geometrik düşünme, problem 
çözme ve ispat becerilerinin, geleneksel öğretmen merkezli geometri dersleri sonrasındaki duruma göre farklı olup olmadığıdır. $\mathrm{Bu}$ nedenle, geometri derslerinde dinamik geometri etkinliklerinin uygulandığı deney grubu ile bu etkinliklerin uygulanmadığı kontrol grubu oluşturulmuştur.

\section{Evren ve Örneklem}

Araştırmaya, İstanbul ilinde bilgisayar laboratuvarına sahip Anadolu lisesi statüsündeki 6 lise katılmıştır. Okulların gruplara dağılımı, idari nedenlerden dolayı, matematik zümrelerinin tercihine bırakılmıştır. Okulların üç tanesi deney grubunda, iki tanesi kontrol grubunda yer almış, bir okulda ise bir sınıf deney, bir sınıf kontrol grubu olarak belirlenmiştir. Buna göre 145 (\%64) öğrenci deney grubunda 82 (\%36) öğrenci kontrol grubunda olmuştur. Ön testler tüm öğrencilere ama son testler 98 öğrenciye uygulanabilmiştir. Ancak her iki aşamada tüm testleri alan 49 öğrenciye ait veriler analiz edilmiştir. Bu öğrencilerin 12'si (\%24) deney grubunda, 37'si (\%76) kontrol grubundadır. Çalışmalar, deney grubunda ve kontrol grubunda dörder öğretmen tarafından yürütülmüştür. Deney grubundaki öğretmenlere kullanılacak olan dinamik geometri yazılımı ve uygulanacak etkinlikler hakkında hizmetiçi eğitim verilmiştir.

\section{Veri Toplama Araçları}

$\mathrm{Bu}$ çalışmada, öğrencilerin geometrik düşünme, problem çözme ve ispat yapma becerilerini ölçmeye yönelik, yazılı yoklama türünde, üç çeşit test uygulanmıştır: Geometrik Düşünme Testi (GDT), Geometri Başarı Testi (GBT) ve Geometri İspat Testi (GIT). Bu testler, 10. sınıf geometri dersinin Üçgenler ve Dönüşümlerle Geometri ünitelerinde yer alan bazı kazanımlara yönelik sorular içermektedir. Testler, test-tekrar test şeklinde çalışma öncesi ve sonrasında uygulanmıştır.

Uygulanan testlerin her biri 100 puan değerindedir. GDT, yedi maddeden oluşmaktadır ve puan dağglımı sırasıyla $30,9,9,8,12,12$ ve 20 'dir. Bu testin 1 . maddesinde 15 tane geometri kavramının (ör:, doğru, açı, kenarortay, üçgenin iç merkezi, vb.) tanımı sorulmuştur. Testin, 2., 3. ve 4. maddeleri üçgenlerde kenar-açı bağıntılarının tanımlanması veya ispat edilmesine yöneliktir. Testin 5. maddesi dönüşüm geometrisi, 6. maddesi ise eş üçgenlerle ilgilidir. Son maddede öğrencilere 4 alt soru verilmiş, sorularda verilen bilgileri kullanarak belirtilen şekli çizmeleri istenmiştir (ör: $\mathrm{ABC}$ bir üçgen, $|\mathrm{AB}|=|\mathrm{AC}|$, A açısının iç açıortayı ile AC kenarının kenarortayının kesim noktası P). Testte yer alan maddelerin seçiminde işlenen ünitelerin içeriği, van Hiele'nin geometrik düşünme seviyeleri (Usiskin, 1982) ve Driscoll'un 
(2007) aklın geometrik alışkanlıkları dikkate alınmıştır. GBT, 10 maddeden oluşmuştur ve her bir madde 10 puan değerindedir. GBT'de üçgen eşitsizliği, açıortay, kenarortay, Öklit, Pisagor ve Menalaus teoremleri, benzerlik ve eşlik ve dönüşüm geometrisine ilişkin maddeler vardır. GBT maddelerinin seçiminde geometri ders kitaplarından yararlanılmıştır. GIT, altı maddeden oluşmaktadır ve 3. ve 6. maddeler 20'şer puan, diğerleri 15 'er puandır. Bu testte, üçgende bir dış açının ölçüsü, üçgende kenar-açı bağıntısı, üçgenin alanı, Sinüs, Carnot ve Öklit teoremlerinin ispatı sorulmaktadır. Bu maddeler, işlenen ünitelerde yer alan ispatları kapsamaktadir.

Çalışma, 2011-2012 öğretim yılının Mart-Mayıs ayları arasındaki toplam 12 hafta boyunca devam etmiştir. Dinamik geometri etkinliklerinin ders işlenişsine paralel olarak yapılması öngörülmüş ve dönem boyunca beş etkinlik yapılmıştır. Etkinlikler; üçgende kenaraçı bağıntıları, açıortay-kenarortay-orta dikme ve özelliklerini, dönüşüm geometrisini, ÖklitMenalaus-Ceva ve Carnot teoremlerini kapsamaktadır. Etkinlikler, dersin öğretmeni gözetiminde, bilgisayar laboratuvarında öğrenciler tarafından gerçekleştirilmiştir. Dinamik geometri ortamında Geometers' Sketchpad (GSP) yazılımı kullanılmıştır.

\section{Veri Analizi}

$\mathrm{Bu}$ çalışmada toplanan veriler, istatistiksel analiz yapabilen bir bilgisayar programı kullanılarak analiz edilmiştir. Kullanılan testlerin geçerlik analizi için kapsam ve uyum geçerliğine bakılmıştır. Kapsam geçerliği için uygulamaların yapılacağı iki üniteye ait kazanımlar belirlenerek belirtke tablosu hazırlanmış her bir test için soru maddeleri sınav amacına ve sınav süresine göre belirlenmiştir. Uyum geçerliliği için testler arasındaki korelasyona bakılmıştır. Güvenirlik için test-tekrar test güvenirliği ve puanlama güvenirliği incelenmiştir. Puanlama güvenirliği için her bir teste özel puanlama cetveli hazırlanmış, testler iki uzman tarafindan değerlendirilmiştir. Ayrıca, öğrencilerin testlerde yer alan soru maddelerine verdikleri yanıtlara ilişkin betimsel bazı analizler de yapılmıştır.

\section{Bulgular ve Yorumlar}

\section{Geçerlik ve Güvenirlik}

Testlerin geçerlik analizi için kapsam ve uyum geçerliğine bakılmıştır. Bir matematik eğitimi uzmanı ile üç deneyimli öğretmen, testlerin hedeflenen kazanımlar ve testin amacı doğrultusunda kapsamının uygun olduğunu belirtmiştir. Uygulanan testlerin hem ön test hem de son test aşamasında uyum geçerliğine bakılmış, anlamlı sonuçlar elde edilmiştir. Buna göre 
son test aşamasında GDT ile GBT arasındaki Pearson korelasyonu .60 ( $\mathrm{p}=.000)$, GDT ile GİT arasındaki korelasyon $.43(\mathrm{p}=.002)$, ve GBT ile GİT arasındaki korelasyon .54 ( $\mathrm{p}=.000)$ olarak bulunmuştur. Testlerin güvenirlik analizi için puanlama ve test-tekrar test güvenirliğine bakılmıştır. Testlerin puanlaması iki uzman tarafından yapılmış, GDT testinin puanlama güvenirliği 0.96 , GBT testinin 0.98 ve GİT testinin ise 1.00 bulunmuştur. GDT ve GBT testinde yer alan farklı puanlamalar için test maddeleri puanlama cetveli 1şı̆̆ında tekrar gözden geçirilmiş ve ortak karara varılmıştır. Test-tekrar test güvenirlik analizine göre, GDT testinin test-tekrar test Pearson korelasyonu $.56(\mathrm{p}=.000)$, GBT testinin Pearson korelasyonu $.67(\mathrm{p}=.000)$ ve GİT testinin korelasyonu .68 $(\mathrm{p}=.000)$ olarak hesaplanmıştır.

\section{Dinamik Geometri Etkinliklerinin Etkisi}

Çalışmaya katılan 227 öğrencinin 49'u hem ön test aşamasında hem de son test aşamasında tüm testlere girmiştir. Diğerlerinin ya son test aşamasındaki tüm testleri eksik ya da ön test aşamasında veya son test aşamasında eksik testleri vardır. Bu nedenle, 49 öğrenciye ait test sonuçları analiz edilmiştir. Bu testlere ilişkin betimsel istatistikler Tablo 1'de verilmiştir.

Tablo 1 GDT, GBT ve GIT Testlerine İlişkin Betimsel İstatistikler

\begin{tabular}{|c|c|c|c|c|c|c|c|c|c|c|}
\hline & \multicolumn{5}{|c|}{ Deney Grubu } & \multicolumn{5}{|c|}{ Kontrol Grubu } \\
\hline & $\mathrm{N}$ & Min. & Max. & $\bar{X}$ & $\mathrm{~s}_{\overline{\mathrm{x}}}$ & $\mathrm{N}$ & Min. & Max. & $\bar{X}$ & $\mathrm{~s}_{\overline{\mathrm{x}}}$ \\
\hline GDT Ön test & 12 & 7 & 55 & 30.08 & 14.34 & 37 & 7 & 67 & 39.73 & 14.50 \\
\hline GDT Son test & 12 & 22 & 63 & 43.42 & 14.59 & 37 & 7 & 81 & 44.70 & 19.89 \\
\hline GBT Ön test & 12 & 0 & 33 & 9.25 & 10.50 & 37 & 0 & 47 & 16.68 & 13.14 \\
\hline GBT Son test & 12 & 0 & 48 & 21.17 & 11.51 & 37 & 0 & 82 & 31.27 & 23.51 \\
\hline GİT Ön test & 12 & 0 & 13 & 3.17 & 4.99 & 37 & 0 & 60 & 15.73 & 14.97 \\
\hline GİT Son test & 12 & 0 & 20 & 7.92 & 5.42 & 37 & 0 & 45 & 12.11 & 12.20 \\
\hline
\end{tabular}

Öğrencilerin ön test uygulamasında GDT, GBT ve GİT testlerinden aldıkları en yüksek puanlar sirasiyla 67,47 ve 60'tır. Son test uygulamasinda ise bu puanlar sirasiyla 81,82 ve 45 olmuştur. GDT testi dışındaki testlerde, hem ön test aşamasında hem de son test aşamasında hiç puan alamayan öğrenciler bulunmaktadır. Testlerin ortalamaları 50 puanının altında olup, öğrencilerin puanları arasındaki farklılıklar fazladır (ör: kontrol grubunda GBT son testinin standart sapması 23.51'dir). Grupların ön test sonuçları karşılaştırıldığında, GDT ( $\mathrm{t}_{47}$, $.05=2.007, \mathrm{p}=.050)$ ve GBT $\left(\mathrm{t}_{47}, .05=1.778, \mathrm{p}=.082\right)$ testlerinin ortalamalar1 arasinda anlaml bir fark bulunmazken GIT $\left(\mathrm{t}_{47}, .05=4.405, \mathrm{p}=.000\right)$ testinde kontrol grubu lehine bir fark 
bulunmuştur. GDT, GBT ve GITT türünde son testler karşılaştırıldığında ise gruplar arasında anlamlı bir fark bulunmamıştır (sırasıyla; $\mathrm{t}_{47}, .05=.206, \mathrm{p}=.838, \mathrm{t}_{47}, .05=1.982, \mathrm{p}=.055$, ve $\mathrm{t}_{47}$, $.05=1.639, \mathrm{p}=.109)$. Ön testlerde, tüm test türlerinde, gruplar arasında eş bir dağılım gözlenmediği için grup içinde ön test ve son test ortalamaları karşılaştırılmıştır. Deney grubunda her üç türde son testin ortalamasında anlamlı artışlar gözlenmiştir. Elde edilen sonuçlar şu şekildedir: GDT için $\mathrm{t}_{11, .05}=2.945, \mathrm{p}=.013$; GBT için $\mathrm{t}_{11, .05}=3.856, \mathrm{p}=.003$; ve GIT için $\mathrm{t}_{11, .05}=2.844, \mathrm{p}=.016$. Kontrol grubunda ise sadece GBT testinde anlamlı bir artış gözlenmiş $\left(\mathrm{t}_{36, .05}=5.562, \mathrm{p}=.000\right)$, GDT $\left(\mathrm{t}_{36, .05}=2.025, \mathrm{p}=.050\right)$ ve GIT $\left(\mathrm{t}_{36, .05}=1.980, \mathrm{p}=.055\right)$ için anlamlı farklılıklar elde edilmemiştir. Örneklem sayısı küçük olduğu için deney grubuna Wilcoxon Signed Rank Test de uygulanmıştır. Elde edilen sonuçlar şu şekildedir: GDT için $\mathrm{z}=-2.432, \mathrm{p}=.015$; GBT için $\mathrm{z}=-2.701, \mathrm{p}=.007$; ve GIT için $\mathrm{z}=-2.174, \mathrm{p}=.030$. Bu sonuçlar $\mathrm{t}-$ testi sonuçlarıyla örtüşmektedir.

Deney grubunda, ön test ve son testte, öğrencilerin her bir maddeden aldıkları puanlar da Wilcoxon Signed Rank Test uygulanarak karşılaştırılmıştır. Buna göre, GDT testinde 3. maddede (üçgen oluşturma-çizme), 4. maddede (üçgende kenar-açı bağıntısı) ve 7. maddede (şekil oluşturma) anlamlı değişimler gözlenmiştir ( $\mathrm{p} \leq .05$ olmak üzere, sırasıyla, $\mathrm{z}=-2.66, \mathrm{z}=$ 2.19 ve $z=-2.62$ ). GBT testinde ise 1 . maddedeki (üçgende kenar-açı bağıntısı), 2. maddedeki (açıortay teoremi) ve 3. maddedeki (kenarortay teoremi) artışlar anlamlıdır ( $\mathrm{p} \leq .05$ olmak üzere, sırasılya, $\mathrm{z}=-2.10, \mathrm{z}=-2.36$ ve $\mathrm{z}=-2.80$ ). GíT testinde ise sadece 1 . maddede (dış açının ölçüsü) anlamlı bir fark bulunmuştur ( $\mathrm{p} \leq .05$ olmak üzere, $\mathrm{z}=-2.24)$. Ayrıca, dinamik geometri etkinliklerinin kapsamı ile bu maddelerin içeriklerinin örtüştüğü de tespit edilmiştir.

\section{Öğrencilerin Geometriye İlişkin Bilgi Düzeyleri}

Öğrencilerin tüm test türlerinde her bir test maddesine verdikleri yanıtlar ve aldıkları puanlar da incelenmiştir. Öğrencilerin test maddelerinden aldıkları puanlara ilişsin betimsel istatistikler Tablo 2'de verilmiştir.

Elde edilen sonuçlara göre, GDT testinde ağırlıklı ortalaması en yüksek olan madde 7 . madde (şekil oluşturma), en düşük olan madde ise 2. maddedir (kenar-açı bağıntısı). GBT ve GITT testlerinde öğrencilerin başarısı oldukça düşük olup GBT'de 6. maddenin (benzerlik) ve GITT’te de 1. maddenin (dış açının ölçüsü) ortalaması diğerlerine göre yüksektir. Öğrencilerin geometriye ilişkin bilgi düzeyleri hakkında destek veri sağlaması amacıyla, test maddelerine verdikleri yanıtlar da incelenmiştir. Bu bağlamda öncelikle GDT testinin 1. maddesinde sorulan temel geometri kavramlarına verdikleri yanıtlar analiz edilmiştir. Çünkü bu madde 
hem Bloom taksonomisine göre bilişsel alanda ilk bilgi düzeyidir hem de van Hiele'nin analitik düzeyine denk gelmektedir.

Tablo 2 Test Maddelerine İlişkin Betimsel İstatistikler

\begin{tabular}{cccccccccccccccccccc}
\hline Madde & $\mathrm{N}$ & Min. & Max. & $\overline{\mathrm{X}}$ & $\mathrm{s}_{\overline{\mathrm{X}}}$ & Madde & $\mathrm{N}$ & Min. & Max. & $\overline{\mathrm{X}}$ & $\mathrm{s}_{\overline{\mathrm{X}}}$ & Madde & $\mathrm{N}$ & Min. & Max. & $\overline{\mathrm{X}}$ & $\mathrm{s}_{\overline{\mathrm{X}}}$ \\
\hline GDT1 & 49 & 0 & 23 & 11.92 & 5.88 & GBT1 & 49 & 0 & 10 & 3.39 & 3.14 & GiT1 & 49 & 0 & 15 & 6.53 & 5.52 \\
GDT2 & 49 & 0 & 6 & 2.80 & 1.78 & GBT2 & 49 & 0 & 10 & 3.29 & 3.94 & GiT2 & 49 & 0 & 5 & 1.43 & 2.28 \\
GDT3 & 49 & 0 & 9 & 4.71 & 2.45 & GBT3 & 49 & 0 & 10 & 4.84 & 4.05 & GiT3 & 49 & 0 & 15 & 1.69 & 3.95 \\
GDT4 & 49 & 0 & 8 & 3.31 & 2.82 & GBT4 & 49 & 0 & 10 & 1.86 & 2.80 & GiT4 & 49 & 0 & 5 & .51 & 1.53 \\
GDT5 & 49 & 0 & 12 & 4.29 & 4.77 & GBT5 & 49 & 0 & 10 & 1.84 & 2.73 & GíT5 & 49 & 0 & 5 & .10 & .71 \\
GDT6 & 49 & 0 & 12 & 6.00 & 3.25 & GBT6 & 49 & 0 & 10 & 5.61 & 4.48 & GiT6 & 49 & 0 & 20 & .82 & 4.00 \\
GDT7 & 49 & 0 & 19 & 11.41 & 6.03 & GBT7 & 49 & 0 & 10 & 2.57 & 3.61 & & & & & & \\
& & & & & GBT8 & 49 & 0 & 10 & 2.20 & 3.19 & & & & & & \\
& & & & & GBT9 & 49 & 0 & 10 & 1.47 & 3.13 & & & & & & \\
& & & & & GBT10 & 49 & 0 & 10 & 1.73 & 3.32 & & & & & & \\
\hline
\end{tabular}

GDT testinin ilk maddesinde öğrencilere, işlenen ünitelerde yer alan 15 kavramın tanımı sorulmuştur. Öğrencilerin büyük bir kısmı kavramları doğru olarak tanımlayamamış, bazıları tanım yerine o geometrik kavramı ifade eden şekli çizmiş, birkaçı hem tanımı yapıp hem de şekli çizmiş, bir kısmı ise soruyu yanıtlamamıştır. Kavramın şeklini yanlış çizenler veya kavramı yanlış tanımlayıp şeklini doğru çizen öğrenciler de bulunmaktadır. Bu maddeye ilişkin betimsel sonuçlar Tablo 3 'te verilmiştir.

Tabloya göre, öğrencilerin açıortay, kenarortay, üçgenin ağırlık merkezi, öteleme ve benzer üçgenler kavramlarını doğru tanımlama yüzdeleri bu kavramları yanlış tanımlayanlara göre büyüktür. Öğrencilerin doğru, doğru parçası, 1şın, açı, üçgen gibi temel kavramları ise tanımlayamadıkları görülmektedir. Öğrencilerin çoğu doğru kavramını "sonsuza kadar giden çizgi", "sonsuz noktalar kümesi" veya "sonu ve başı belli olmayan" şeklinde ifade etmişlerdir. Doğru parçası için ise "iki yönü de kapalı olan parça" veya "sonu ve başı belli çizgi” şeklinde ifadeler kullanmışlardır. Öğrenciler, ışın kavramını "başlangıcı belli sonu belli olmayan çizgi", "başlangıcı belli diğer ucu sonsuza kadar gider" veya "bir ucu kapalı diğer ucu açıktır" şeklinde, açı kavramını "iki doğru arasında kalan yer / derece / alan / ölçü” şeklinde ve üçgen kavramını da "üç tane doğru parçasının birleşimi”, “üç köşeli geometrik şekil” veya "üç açıdan oluşan üç kenarlı geometrik şekil” şeklinde ifade etmişlerdir. Ayrıca, öğrencilerin ortadikme, üçgenin diklik merkezi, üçgenin iç merkezi, üçgenin çevrel çemberi ve yansıma ekseni hakkında bilgi sahibi olmadıkları da görülmüştür. Öğrenciler, ortadikmeyi "kenarı 
ortalayan dik" , "bir kenarla dik açı oluşturacak şekilde çakışmış doğru” veya "iki açıdan geçen doğruların kesişimlerinin dik olması" şeklinde, üçgenin diklik merkezini “dik kenarların kesiştiği köşe", "üçgenin dikmelerinin kesiştiği yerdir" veya "üçgenin kenarlarından çizilen doğruların dik olacak bir biçimde kesişmesi” şeklinde, üçgenin iç merkezini, "üçgenin iç kısmı”, “üçgenin dik kesen orta dikmenin orta noktası" veya "ağırlık merkezi” şeklinde, üçgenin çevrel çemberini “üçgenin dışındaki çember” veya “üçgenin üç kenarının da üzerinde bulunduğu onu saran çember" şeklinde ve yansıma eksenini "bir cismin tersinin çizilmesinde kullanılan eksen", "x eksenine veya y eksenine göre olur" veya "nesnenin aynadan yansıma hali” şeklinde ifade etmişlerdir.

Tablo 3 GTD Testinin İlk Maddesine İlişkin Sonuçlar

\begin{tabular}{|c|c|c|c|c|c|c|c|c|c|c|c|c|c|c|c|c|c|c|c|c|c|c|c|c|}
\hline $\mathrm{K}$ & Tür & Yanit & $\mathrm{f}$ & $\%$ & $\mathrm{~K}$ & Tür & Yanit & $\mathrm{f}$ & $\%$ & $\mathrm{~K}$ & Tür & Yanit & $\mathrm{f}$ & $\%$ & $\mathrm{~K}$ & Tür & Yanit & $\mathrm{f}$ & $\%$ & K & Tür & Yanit & $\mathrm{f}$ & $\%$ \\
\hline \multirow{9}{*}{ 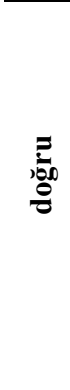 } & \multirow{2}{*}{ Ş } & $\mathrm{D}$ & 4 & 8 & & \multirow[b]{2}{*}{ Ş } & $\mathrm{D}$ & 8 & 16 & \multirow{9}{*}{ 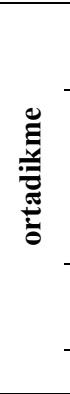 } & \multirow[b]{2}{*}{ Ş } & $\mathrm{D}$ & 0 & 0 & \multirow{2}{*}{$\bar{d}$} & \multirow{2}{*}{ Ş } & $\mathrm{D}$ & 2 & \multirow{2}{*}{\multicolumn{2}{|c|}{4}} & \multirow{2}{*}{ Ş } & $\mathrm{D}$ & 5 & 10 \\
\hline & & $\mathrm{Y}$ & 1 & 2 & & & $\mathrm{Y}$ & 0 & 0 & & & $\mathrm{Y}$ & 6 & 12 & & & $\mathrm{Y}$ & 6 & & & & $\mathrm{Y}$ & 0 & 0 \\
\hline & & DD & 1 & 2 & \multirow{7}{*}{$\bar{\sigma}$} & \multirow{4}{*}{ ŞT } & DD & 1 & 2 & & \multirow{4}{*}{ ŞT } & $\mathrm{DD}$ & 1 & 2 & $\bar{\Xi}$ & \multirow{4}{*}{ ŞT } & $\mathrm{DD}$ & 0 & 0 & \multirow{7}{*}{ 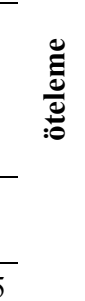 } & \multirow{4}{*}{ ŞT } & DD & 2 & 4 \\
\hline & \multirow{3}{*}{ ŞT } & $\mathrm{DY}$ & 4 & 8 & & & DY & 4 & 8 & & & DY & 0 & 0 & \multirow{6}{*}{ 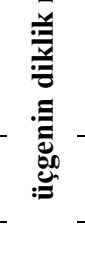 } & & $\mathrm{DY}$ & 0 & 0 & & & DY & 0 & 0 \\
\hline & & YD & 0 & 0 & & & YD & 0 & 0 & & & YD & 0 & 0 & & & YD & 0 & 0 & & & YD & 0 & 0 \\
\hline & & YY & 0 & 0 & & & YY & 0 & 0 & & & YY & 7 & 14 & & & $\mathrm{YY}$ & 1 & 2 & & & YY & 0 & 0 \\
\hline & \multirow{3}{*}{$\mathrm{T}$} & $\mathrm{D}$ & 5 & 10 & & \multirow{3}{*}{$\mathrm{T}$} & $\mathrm{D}$ & 3 & 6 & & \multirow{3}{*}{$\mathrm{T}$} & $\mathrm{D}$ & 9 & 18 & & \multirow{3}{*}{$\mathrm{T}$} & $\mathrm{D}$ & 4 & 8 & & T & $\mathrm{D}$ & 24 & 49 \\
\hline & & $\mathrm{Y}$ & 32 & 65 & & & $\mathrm{Y}$ & 30 & 61 & & & $\mathrm{Y}$ & 15 & 31 & & & $\mathrm{Y}$ & 21 & 43 & & 1 & $\mathrm{Y}$ & 10 & 20 \\
\hline & & Boss & 2 & 4 & & & Boş & 3 & 6 & & & Boss & 11 & 22 & & & Boş & 17 & 35 & & & Boş & 8 & 16 \\
\hline & & $\mathrm{D}$ & 5 & 10 & & & D & 3 & 6 & & & $\mathrm{D}$ & 5 & 10 & & & $\mathrm{D}$ & 1 & 2 & & & $\mathrm{D}$ & 5 & 10 \\
\hline & \$̧ & $\mathrm{Y}$ & 0 & 0 & & \$̧ & $\mathrm{Y}$ & 1 & 2 & & ફ̧ & $\mathrm{Y}$ & 0 & 0 & $s$ & ş & $\mathrm{Y}$ & 4 & 8 & & Ş & $\mathrm{Y}$ & 0 & 0 \\
\hline 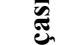 & & DD & 3 & 6 & & & DD & 2 & 4 & & & DD & 5 & 10 & 产 & & $\mathrm{DD}$ & 0 & 0 & & & $\mathrm{DD}$ & 2 & 4 \\
\hline 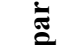 & ST & DY & 3 & 6 & 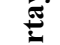 & ST & DY & 2 & 4 & $\Xi$ & ST & DY & 1 & 2 & in & ST & DY & 0 & 0 & & ST & DY & 1 & 2 \\
\hline$E$ & उु1 & YD & 0 & 0 & $\stackrel{\varrho}{2}$ & Ş1 & YD & 0 & 0 & 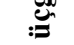 & Ş1 & YD & 0 & 0 & $\Xi$ & Ş1 & YD & 0 & 0 & $\underline{\Xi}$ & \$̧1 & YD & 0 & 0 \\
\hline & & YY & 0 & 0 & & & YY & 0 & 0 & & & YY & 0 & 0 & $\exists$ & & YY & 0 & 0 & స & & YY & 0 & 0 \\
\hline & T & D & 13 & 27 & & T & D & 26 & 53 & & T & D & 13 & 27 & $\cong$ & $T$ & D & 7 & 14 & & T & D & 11 & 22 \\
\hline & 1 & $\mathrm{Y}$ & 21 & 43 & & 1 & $\mathrm{Y}$ & 12 & 24 & & 1 & $\mathrm{Y}$ & 25 & 51 & & 1 & $\mathrm{Y}$ & 18 & 37 & & 1 & $\mathrm{Y}$ & 20 & 41 \\
\hline & & Boş & 4 & 8 & & & Boş & 3 & 6 & & & Boş & 0 & 0 & & & Boş & 19 & 39 & & & Boş & 10 & 20 \\
\hline & S & $\mathrm{D}$ & 3 & 6 & & S & $\mathrm{D}$ & 3 & 6 & & S & $\mathrm{D}$ & 2 & 4 & & S & $\mathrm{D}$ & 7 & 14 & & S & $\mathrm{D}$ & 6 & 12 \\
\hline & 3 & $\mathrm{Y}$ & 1 & 2 & & 3 & $\mathrm{Y}$ & 1 & 2 & & S & $\mathrm{Y}$ & 5 & 10 & & S & $\mathrm{Y}$ & 2 & 8 & & S & $\mathrm{Y}$ & 1 & 2 \\
\hline & & DD & 1 & 2 & & & DD & 2 & 4 & $\bar{I}$ & & $\mathrm{DD}$ & 3 & 6 & & & DD & 1 & 2 & $\bar{\Xi}$ & & DD & 0 & 0 \\
\hline$\Xi$ & S' & DY & 5 & 10 & 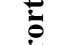 & & DY & 0 & 0 & . & & DY & 2 & 4 & 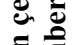 & & DY & 0 & 0 & $\stackrel{\infty}{=0}$ & & DY & 0 & 0 \\
\hline 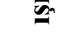 & \$̧। & $\begin{array}{l}\text { YD } \\
\end{array}$ & 0 & 0 & ๘ँ & \$̧1 & YD & 1 & 2 & 浔 & & YD & 0 & 0 & 跑 & & YD & 1 & 2 & $\overline{\bar{v}}$ & S1 & YD & 0 & 0 \\
\hline & & YY & 0 & 0 & $\nsubseteq$ & & YY & 4 & 8 & & & YY & 0 & 0 & & & YY & 0 & 0 & & & YY & 1 & 2 \\
\hline & T & $\mathrm{D}$ & 8 & 16 & & T & $\mathrm{D}$ & 22 & 45 & & T & $\mathrm{D}$ & 16 & 33 & & $\mathrm{~T}$ & $\mathrm{D}$ & 10 & 20 & & $\mathrm{~T}$ & $\mathrm{D}$ & 21 & 43 \\
\hline & & $\mathrm{Y}$ & 26 & 53 & & & $\mathrm{Y}$ & 12 & 24 & & & $\mathrm{Y}$ & 13 & 27 & & & $\mathrm{Y}$ & 14 & 29 & & & $\mathrm{Y}$ & 17 & 35 \\
\hline & & Boș & 5 & 10 & & & Boş & 4 & 8 & & & Boș & 8 & 16 & & & Boş & 14 & 29 & & & Boş & 3 & 6 \\
\hline
\end{tabular}

K: Kavram, Ş:Şekil, T:Tanım, ŞT: Şekil ve Tanım, D: Doğru, Y: Yanlış, f: Frekans

Öğrencilerin doğru tanımladıkları kavramlara ilişkin GDT veya GBT testindeki maddeleri doğru yanıtlayıp yanıtlayamadıkları da incelenmiştir. Buna göre, benzer üçgenler kavramını doğru tanımlayan veya şekil ile doğru ifade eden 27 öğrencinin 18'i GBT 
testindeki benzerlik ile ile ilgili maddeyi doğru yanıtlamıştır. Bununla beraber, benzer üçgenler tanımını yapamayan dört öğrenci benzerlik sorusunu çözebilmiştir. Diğer taraftan, GDT testinde yer alan eş üçgenlerin ayırt edilmesine ilişkin maddeyi 27 öğrencinin sadece 8'i doğru yanıtlamış, diğer öğrenciler eş üçgenleri değil benzer üçgenleri bulmuşlardır. Aynı şekilde, öteleme kavramını doğru olarak ifade eden 31 öğrencinin 19'u GDT testindeki öteleme ile ilgili maddeyi doğru olarak yanıtlamış, tanımı yapamayan iki öğrenci de soruyu doğru yapmıştır. GDT testinin son maddesinde öğrencilerin istenilen şekilleri çizebilmesi için temel kavramları açı, açırtay, diklik gibi doğru tanımlamaları gerekmektedir. Her ne kadar öğrencilerin çoğu (\%77) açıortay kavramını doğru ifade etmiş olsa da (açıyı iki eş parçaya bölen doğru veya 1şın) üçgende açırtayı bir doğru parçası olarak algılamış, açırtayın üçgenin kenarlarını keserek dış bölgesine uzanabileceğini düşünmemiştir. Bu nedenle, son maddede yer alan ve açırtayın bir ışın olarak düşünülmesini gerektiren bir soruyu sadece üç öğrenci doğru olarak çizebilmiş, diğerleri yanlış şekiller oluşturmuşlardır. Ayrıca, öğrencilerin GBT testinde açıortay, kenarortay ve ağırlık merkezi ile ilgili uygulamalar yapmayı gerektiren maddeleri de yanıtlayamadıkları görülmüştür.

Öğrenciler, temel geometrik kavramların uygulanmasına yönelik maddeleri içeren GBT testinde çoğu maddeyi yanıtsız bırakmış, bir kısmı sadece soru maddesinde verilen bilgileri şekil üzerinde göstermiş, gerekli işlemleri yapmamıştır. Maddeleri yanıtlamaya çalışanların çoğu mantıksal veya işlem hataları yapmışlardır. Örneğin, GBT testinin ilk maddesinde öğrencilerin geniş açılı bir üçgende üçgen eşitsizliğini uygulamaları beklenmektedir. Öğrenciler, geniş açıyı göz ardı ederek üçgen eşitsizliğini uygulamışlar ve yanlış sonuç bulmuşlardır. Bu soruyu yanıtlamaya çalışan 23 öğrencinin 18'i aynı hatayı yapmış sadece 5'i doğru yanıtlayabilmiştir. GíT testinde de öğrencilerin çoğu test maddelerini yanıtsız bırakmışlardır. Öğrencilerden sadece biri dört ispat üzerinde çalışmış, bunlardan bir tanesini tam olarak ispatlayabilmiştir. Beş öğrenci ise üç ispat üzerinde çalışmış ama hiçbiri ispatların hepsini doğru olarak yapamamıştır. Verilen ispatları yapmaya çalışan 39 öğrencinin 19’u ispatın doğruluğunu örnek vererek göstermiştir. Örneğin, üçgende bir dış açının kendisine komşu olmayan iç açıların toplamı olduğunu göstermek için herhangi bir üçgen çizerek iç açılarını belirtmiş, bir iç açının bütünleri olan dış açıyı bulmuş ve bulduğu bu değerin diğer iki iç açının toplamı olduğunu yazmışlardır. Bu ispatı, doğrudan ispat yöntemini kullanarak yapabilen 11 öğrenci vardır. Öklit teoremlerinin ispatının sorulduğu son maddeyi tam olarak yanıtlayan iki öğrenci vardır. Diğer ispat sorularının hiçbirini tam olarak yapan öğrenci yoktur. 


\section{Sonuç ve Tartışma}

Dinamik geometri yazılımlarının öğrencilerin geometrik düşünme, problem çözme ve ispat yapma becerisine etkisinin araştırılacağı bir projenin ön aşaması olan bu çalışmadan elde edilen bulgular, ana çalışmaya 1şık tutacak nitelikte olup, öğrencilerin geometriye ilişkin bilgi ve becerileri hakkında da önemli veriler sağlamaktadır. Öğrencilerin bu becerilerini ölçmek için üç tür test kullanılmıştır. Elde edilen bulgular, bu testlerin yazılı yoklama tipinde istenilen geçerlik ve güvenirlik seviyesinde olduğunu göstermektedir (Miller, Linn, \& Gronlund, 2009). Uygulanan testlerin uyum geçerliliği ile test-tekrar test güvenirliği istatistiksel olarak anlamlı bulunmuştur. Uygulama öncesi testlerin kapsam geçerliliği uzmanlar tarafından onaylanmıştır ve uygulama sonrası testlerin puanlama güvenirliği de istatistiksel olarak yüksek bulunmuştur. Ancak son test sırasında veri kaybının yaşanması yapılan pilot çalışmanın dış geçerlilik ve güvenirliği konusunda bir zafiyete neden olmuştur.

Öğrencilerin bilişsel becerilerinin gelişmesi için belli etkinliklerin sürekli olarak tekrar edilmesi ve bunun için de belli bir sürenin geçmesi gerekir (Senemoğlu, 2009). Kısa sürede ve sınırlı sayıda etkinlikle öğrencilerin geometrik düşünme, problem çözme ve ispat becerilerinde anlamlı bir artışın olmasını beklemek gerçekçi değildir. Ancak bu çalışmanın bulguları, beş tane GSP etkinliğinin bile öğrencilerin bu becerilerinin gelişimine olumlu katkıda bulunabileceğini göstermektedir. Her ne kadar veriler küçük bir gruba ait olsa da grup içinde farklı okullardan öğrenciler olduğu için oluşan farkın öğretmenden değil GSP'den kaynaklandığını söylemek mümkündür. Deney grubundaki öğrencilerin ön test ve son teste her bir maddeden aldıkları puanlar karşılaştırıldığında, sınıf içinde dinamik geometri etkinliği yapılmış olan kavramlara ilişkin maddelerden aldıkları puanlarda diğerlerine göre anlamlı bir artış olduğu görülmektedir. Öğrenciler özellikle üçgen çizme, üçgende kenar-açı bağıntıları, açıortay-kenarortay kavramlarına ilişkin maddeleri daha doğru bir şekilde yorumlayabilmiş ve yanıtlamışlardır. Dinamik geometri yazılımları öğrencilere şekiller üzerinde rahatça oynama imkanı verdiğinden öğrenci yaptığı herhangi bir değişiklik sonucunda neyin değiștiğini neyin sabit kalığını rahatça görebilmekte ve işlenen kavrama ilişkin doğru bilgileri keşfetme ve öğrenme firsatı yakalamaktadır. Örneğin, herhangi bir üçgende herhangi bir açının ölçüsü büyütüldüğünde karşısındaki kenarın uzunluğu da büyümektedir. Başka bir durumda öğrenci, üçgendeki iç açıortayların tek bir noktada kesiştiğini, bu kesim noktasının daima üçgenin içinde olduğunu, aynı zamanda da bu üçgenin iç merkezi olduğunu görmektedir. Benzer bir durumu üçgenin kenarortaylarında da gözlemleyebilmektedir. Test maddelerinin karşılaştırılmasından elde edilen sonuçlar öğrencilerin üçgende kenar-açı bağıntıları, açıortay 
ve kenarortay kavramlarına ilişkin zihinlerinde doğru bilgiler yapılandırabildiklerini göstermektedir. Alanyazında benzer çalışmalardan elde edilen bulgular da bu durumu desteklemektedir. Örneğin, Liu ve Cummings (2001), dört ilköğretim öğrencisine dört tane GSP etkinliği vermiş, etkinliklerin öğrencilerin geometrik düşünme becerisine olumlu katkıda bulunduğunu, öğrencilerin soyut olan geometrik kavramları doğru olarak somutlaştırmasını kolaylaştırdığını, öğrencileri keşfetmeye ve problem çözmeye teşvik ettiğini bulmuştur. Ayrıca, July (2001) ve Leong (2002) lise öğrencileriyle çalışmış, çalışmalarının sonunda GSP'nin öğrencilerin geometrik düşünme becerilerine olumlu katkılarının olduğunu bulmuşlardır. Ayrıca, her ne kadar bu çalışmada nitel veri toplama araçları kullanılmamış olsa da öğrencilerin test maddelerine verdikleri yanıtlar, geometriye ilişkin bilgi ve beceri düzeylerine ilişkin veri sağlamaktadır.

Öğrencilerin geometriye ilişkin bilgi ve beceri seviyeleri düşüktür. Bu durum, Türk öğrencilerinin ulusal ve uluslararası sınavlarda gösterdikleri başarıyla paralellik göstermektedir (ÖBBS, 2009; PISA, 2009; TIMSS, 2007). Öğrencilerin geometriye ilişkin bilgi düzeyleri genel olarak kavrama düzeyinde olup, uygulama ve üzeri bilgi düzeylerine erişmiş olan çok az öğrenci bulunmaktadır. Öğrencilerin ispat becerilerinin zayıf olduğu alanyazında yapılan çalışmalar tarafından da ortaya konmaktadır (ör: Arslan \& Yıldız, 2010; Harel \& Sowder, 1998; Hershkowitz ve ark., 2002; Reiss, Klieme, \& Heinz, 2001; Stylianides, 2008). Testlerde yer alan soru maddeleri analiz edildiğinde öğrencilerin çoğunun verilen kavramları matematiksel olarak ifade edemediği görülmüştür. Öğrencilerin, zihinlerindeki kavram görüntüsünden (concept image) yola çıkarak kavramı tanımlamaya (concept definition) çalıştıkları bu nedenle kavrama ilişkin sınırlı, bazen de yanlış bilgiye sahip oldukları söylenebilir (Vinner \& Dreyfus, 1989). Bu durum, öğrencilerin GDT testindeki birinci ve yedinci maddeye verdikleri yanıtlarda ortaya çıkmaktadır. Örneğin, GDT testinin birinci maddesinde öğrenciler açıortayı "bir açıyı ikiye bölen uzunluk" olarak tanımlamakta ve yedinci maddede açıortay çizmesi gerektiğinde üçgenin köşesinden başlayıp karşı kenarda biten bir doğru parçası çizmektedir. Açıortayı doğru olarak tanımlayan öğrencilerin zihninde de benzer bir durum canlandırmaktadır. Öyle ki, açıortayın üçgenin iç bölgesinden dış bölgesine doğru uzanan bir ışın olarak çizilmesini gerektiren bir durumda, açırtayı yine doğru parçası şeklinde çizmiş ve istenilen şekli oluşturamamışlardır. Dinamik geometri yazılımları doğası gereği öğrencilerin zihinlerinde doğru kavram görüntüleri oluşturmalarını destekler. Örneğin, öğrenci bir açının açırtayını çizmek istediğinde açıortay, bir ışın veya doğru olarak çizilir veya geniş açılı bir üçgende dar açılardan kenarlara inilen 
yükseklikler üçgenin kenarını oluşturan doğruyu üçgenin dış bölgesinde keser, yani öğrenci, kenara ait yüksekliğin üçgenin iç bölgesinden geçmek zorunda olmadığını görmüş olur.

Öğrencilerin GBT testindeki başarılarının düşük olması, geometriye ilişkin bilgilerinin bilgi veya kavrama düzeyinde olduğunu, bu bilgilerini uygulamaya geçiremediklerini göstermektedir. $\mathrm{Bu}$ durum, aynı zamanda öğrencilerin geometrik kavramlara ilişkin bilgilerinin yüzeysel olduğunu, kavramlar hakkında derin bilgiye sahip olmadıklarını da göstermektedir. Örneğin, öğrenciler ağırlık merkezini tanımlayabilmekte ancak ağırlık merkezinin kenarortay doğrusu üzerindeki yerleşimini (2:1 oranı) bilmemektedir veya benzer üçgenleri tanımlamakta ancak hangi ölçütlere göre (açı-açı-açı gibi) iki üçgenin benzer olacağını bilmemektedir. Dinamik geometri yazılımları, öğrencilerin kavramlara ait bu tür özelliklerini öğrenmesini de destekleyecek niteliktedir. Öğrenciler, oluşturdukları şekiller üzerinde ölçümler yaparak, herhangi bir açıyı veya kenarı değiştirdiğinde nelerin değiştiğini, nelerin sabit kaldığını, özel durumların neler olduğunu rahatça görebilir. Öğrenme kuramcılarının da belirttiği gibi (Senemoğlu, 2009), ölçümlerle de desteklenen bu görsellik, öğrencilerin ilgili kavramı ve özelliklerini daha iyi anlamasını sağlayacaktır. Dinamik geometri yazılımların bu özelliği, Driscoll'un (2007) aklın geometrik alışkanlıklarından olan bağlantılar arasındaki nedenleri ortaya koyma, geometrik olguları genelleştirme ve değişmezleri inceleme becerilerinin gelişimine de katkıda bulunacaktır.

Gerek GDT testinde yer alan bazı maddelerin gerekse GITT testinin sonuçları öğrencilerin ispat becerilerinin düşük olduğunu göstermektedir. Öğrencilerin kavramlara ilişkin bilgileri ve GBT testi sonuçları gözönüne alındığında daha üst düşünme becerisi olan ispat becerisinde böyle bir sonucun elde edilmesi beklendik bir durumdur. Öğrencilerin ispat becerilerinin düşük olmasının nedenlerinden biri olarak öğretmenlerin derslerinde ispatlara yeterince veya hiç yer vermemesi gösterilebilir. Çalışma yapılan okullardaki öğretmenler, ders saatinin yetersizliği ve öğrencilerin motivasyonunun düşüklüğü nedeniyle her ne kadar öğretim programında yer alsa da ispatlara zaman ayırmadıklarını dile getirmişlerdir. Yalnızca kontrol grubunda yer alan okullarda öğretmenler eşlik, Öklit, Menalus teoremleri gibi bazı ispatlara yer verdiklerini belirtmişlerdir. Bu durum, kontrol grubunun GİT testi sonuçlarından da anlaşılmaktadır. Kontrol grubundaki öğrencilerin ortalaması deney grubundan daha yüksektir ve ön testte bu fark anlamlı iken son testte anlamlı değildir. 


\section{Öneriler}

Ülkemizde lise öğrencilerinin geometriye ilişkin bilgi ve becerileri düşük olmakla birlikte geometri öğretiminin dinamik geometri yazılımlarının kullanımını içeren etkinliklerle zenginleştirilmesi öğrencilerin geometrik düşünme becerilerini ve geometri başarısını olumlu katkılarda bulunacaktır. Pilot çalışmanın bulgularından yola çıkarak ana çalışmada bazı düzenlemeler yapılacaktır. Öncelikle yapılacak deneysel çalışmada gruplar arasında eş bir dağılım sağlanması gerekmektedir. İkinci olarak, her ne kadar uygulanan testlerin geçerlik ve güvenirlikleri kabul edilebilir seviyede olsa da özellikle öğretmenlerin ispatlara yeterince yer vermemesinden dolayı öğrencilerin ispat becerileri ayrı bir test ile değil geometrik düşünme testi içindeki bazı maddelerin değiştirilmesiyle ölçülecektir. İspat becerisi, geometrik düşünme becerileri içinde yer aldığından bu durum yeni testin kapsam geçerliliğini zayıflatmayacaktır. Ayrıca dış geçerlilik ve güvenirliği tehdit edebilecek tüm etkenler (veri kaybı gibi) mümkün olduğunca bertaraf edilecektir. Üçüncü olarak, ana çalışmadaki GSP etkinliklerinin sayısı daha fazla olacaktır. Böylelikle dinamik geometri yazılımlarının öğrenme üzerindeki etkisi daha iyi görülebilecektir. Son olarak, testlerin yanı sıra öğrencilerle yarı-yapılandırılmış görüşmeler yapılacak, nicel verilerle elde edilen sonuçlar nitel verilerle de desteklenebilecektir.

\section{Kaynakça}

Arslan, S., \& Yıldız, C. (2010). 11. sınıf öğrencilerinin matematiksel düşünmenin aşamalarındaki yaşantılarından yansımalar, Ĕgitim ve Bilim, 35, 17-31.

Battista, M. T. (2007). The development of geometric and spatial thinking. In F. K. Lester Jr. (Ed.), Second handbook of research on mathematics teaching and learning (pp. 843908). North Carolina: Information Age Publishing.

Clements, D. H., \& Battista, M. T. (1992). Geometry and spatial reasoning. In D. A. Grouws (Ed.), Handbook of research on mathematics teaching and learning (pp. 420-464). New York: MacMillan.

Driscoll, M. (2007). Fostering geometric thinking: A guide for teachers grades 5-10. New Hampshire: Heinemann.

Güven, B. (2008). Using dynamic geometry software to gain insight into a proof, International Journal of Computers for Mathematical Learning, 13, 251-262.

Harel, G., \& Sowder, L. (1998). Students' proof schemes: Results from exploratory studies. CBMS Issues in Mathematics Education, 7, 234-283. 
Healy, L., \& Hoyles, C. (1999). Visual and symbolic reasoning in mathematics: Making connections with computers. Mathematical Thinking and Learning, 1, 59-84.

Heinze, A., Cheng, Y. H., Ufer, S., Lin, F. L., \& Reiss, K. (2008). Strategies to foster students' competencies in constructing multi-steps geometric proofs: Teaching experiments in Taiwan and Germany. ZDM Mathematics Education, 40, 443-453.

Hershkowitz, R., Dreyfus, T., Ben-Zvi, D., Friedlander, A., Hadas, N., Resnick, T., et al. (2002). Mathematics curriculum development for computerized environments: A designer-research-teacher-learner activity. In L. D. English (Ed.), Handbook of International Research in Mathematics Education (pp. 657-694). New Jersey: Erlbaum.

Jones, K. (2000). Proving a foundation for deductive reasoning: Students' interpretations when using dynamic geometry software and their evolving mathematical explanations. Educational Studies in Mathematics, 44, 55-85.

Jones, K. (2002). Issues in the teaching and learning geometry. In L. Haggarty (Ed.) Aspects of Teaching Secondary Mathematics: Perspectives on Practice (pp.121-139). London: Routledge Falmer.

July, R. A. (2001). Thinking in three dimensions: exploring students' geometric thinking and spatial ability with the Geometer's Sketchpad. Yayınlanmamış doktora tezi, Florida International University, ABD.

Leong, Y. H. (2002). Effects of Geometers' Sketchpad on spatial ability and achievement in transformation geometry among secondary 2 students in Singapore. Yayınlanmamış yüksek lisans tezi, Nanyang Technological University, Singapur.

Liu, L., \& Cummings, R., A (2001). Learning model that stimulates geometric thinking through use of PCLogo and Geometers' Sketchpad, Computers in the Schools, 17, 85104.

Marrades, R., \& Gutierrez, A. (2000). Proofs produced by secondary school students learning geometry in a dynamic computer environment. Educational Studies in Mathematics, 44, $87-125$.

Milli Eğitim Bakanlığı (MEB). (2010). Ortaöğretim geometri dersi 9.-10. sinıflar öğretim programı. Ankara: Komisyon.

Milli Eğitim Bakanlığı Eğitimi Araştırma ve Geliştirme Dairesi Başkanlığı. ÖBBS 2009 Raporu. http://earged.meb.gov.tr/arasayfa.php?g=81 adresinden alınmıştır.

Miller, M. D., Linn, R. L., \& Gronlund, N. E. (2009). Measurement and assessment in teaching. New Jersey: Pearson.

Necatibey Eğitim Fakültesi Elektronik Fen ve Matematik Eğitimi Dergisi

Necatibey Faculty of Education, Electronic Journal of Science and Mathematics Education 
Mullis, I.V.S., Martin, M.O., \& Foy, P. (with Olson, J.F., Preuschoff, C., Erberber, E., Arora, A., Galia, J.), (2008). TIMSS 2007 International mathematics report. Massachusetts: TIMSS \& PIRLS International Study Center.

Olkun, S., \& Altun, A. (2003). İlköğretim öğrencilerinin bilgisayar deneyimleri ile uzamsal düşünme ve geometri başarıları arasındaki ilişki, The Turkish Online Journal of Educational Technology, 2, 86-91.

PISA 2009 Results: What students know and can co - Student performance in reading, mathematics and science (Volume I). http://dx.doi.org/10.1787/9789264091450-en adresinden alınmıştır.

Reiss, K., Klieme, E., \& Heinze, A. (2001). Prerequisites for the understanding of proofs in the geometry classroom. In M. van den Heuvel-Panhuizen (Ed.), Proceedings of the $25^{\text {th }}$ Conference of the International Group for the Psychology of Mathematics Education (pp. 97 - 104). Utrecht University: PME.

Scher, D. (2005). Square or not? Assessing constructions in an interactive geometry software environment. In W. J. Masalaski \& P. C. Elliott (Eds.), Technology supported mathematics learning environments (pp. 113-124). Virginia: NCTM.

Senemoğlu, N. (2009). Gelişim, ögrrenme ve ögretim: Kuramdan uygulamaya. Ankara: Pegem Akademi.

Stylianides, G. J. (2008). An analytical framework of reasoning and proving, For the Learning of Mathematics, 28, 9-16.

Ubuz, B., Üstün, I., \& Erbaş, A. K. (2009). Effect of dynamic geometry environment on immediate and retention level achievements of seventh grade students, Eurasian Journal of Educational Research, 35, 147-164.

Usiskin, Z. (1982). Van Hiele levels and achievement in secondary school geometry (Cognitive Development and Achievement in Secondary School Geometry Project). University of Chicago, ABD.

Vinner, S., \& Dreyfus, T. (1989). Images and definitions for the concept of function. Journal for Research in Mathematics Education, 20, 356-366. 